\title{
Ion-Transfer Voltammetry of Drugs at the Nitrobenzene/Water Interface
}

\author{
Kensuke A RAI, Fumiyo KuSU and Kiyoko TAKamURA \\ School of Pharmacy, Tokyo University of Pharmacy and Life Science \\ 1432-1 Horinouchi, Hachioji, Tokyo 192-03, Japan
}

\begin{abstract}
Ion-transfer voltammetry of calcium antagonists, propranolol, and acetylcholine were carried out by current-scan polarography with an ascending water electrode. The $\mathrm{pH}$ effect of the aqueous phase on the half-wave potential of the ion-transfer voltammogram was examined for each drug. For nicardipine, barnidipine and benidipine, the half-wave potential became more positive by $0.059 \mathrm{~V}$ per unit $\mathrm{pH}$ over the $\mathrm{pH}$ range ( $\mathrm{pH} 4-8)$. For propranolol, the half-wave potential became more positive by $0.059 \mathrm{~V}$ per unit $\mathrm{pH}$ at $\mathrm{pH}$ values above 6.8 , whereas at $\mathrm{pH}$ values below 6.8 , this potential remained constant. The half-wave potential of acetylcholine was independent of $\mathrm{pH}$ at $\mathrm{pH}$ 5-8.5. These results could be explained by the $E_{1 / 2}$ equations of for ion transfer of drugs based on the ionization of drugs in the aqueous phase and distribution of neutral drugs between the nitrobenzene and aqueous phases.
\end{abstract}

Keywords Ion-transfer voltammetry, drug, calcium antagonists, propranolol, acetylcholine

The interfaces between the lipid and aqueous phases in a biological system play an important roll in drug transport across a biomembrane and the occurrence of pharmaceutical activity of drugs. ${ }^{1}$ An immiscible oil/water interface is the simplest model of such an interface. Ion-transfer voltammetry serves as a method for clarifying drug behavior at the polarized oil/water interface and thus is of interest from pharmaceutical as well as electroanalytical viewpoints. This method provides thermodynamic parameters such as the free energy of ion transfer and the partition coefficient. Iontransfer voltammetry at the polarized oil/water interface was established by Gavach et $a l .,{ }^{2}$ and has been used to examine the ion transfer of various types of drugs. ${ }^{3}$

Most of these drugs are weak electrolytes. Recently, ${ }^{4}$ ion-transfer voltammetry drugs of weak bases was examined using scopolamine and lidocaine. Half-wave potential $\left(E_{1 / 2}\right)$ equations were derived on the basis of the ionization of drugs in the aqueous phase and the distribution of neutral drugs between the nitrobenzene and aqueous phases. Thus, ion-transfer voltammetry of other cationic drugs is a further point of interest.

In this study, ion-transfer voltammetry of calcium antagonists, propranolol, and acetylcholine were conducted at the nitrobenzene/water interface and the $\mathrm{pH}$ dependence of $E_{1 / 2}$ is discussed. The calcium antagonists in this study and propranolol are amines, and acetylcholine is a quaternary ammonium ion. The $\mathrm{pH}$ dependence of $E_{1 / 2}$ will be explained by the equation of $E_{1 / 2}$ for ion transfer of drugs based on the ionization of the drugs in the aqueous phase and distribution of the neutral drugs between the nitrobenzene and aqueous phases.

\section{Experimental}

\section{Apparatus}

Current-scan polarography at an ascending water electrode ${ }^{5}$ was applied to the measurement of the ion-transfer voltammograms. A drop of aqueous solution was introduced into a nitrobenzene solution from the tip of a Teflon capillary $(0.5 \mathrm{~mm}$ inner diameter and $0.75 \mathrm{~mm}$ length). A capillary $(0.5 \mathrm{~mm}$ inner diameter and 2 $m$ length) was inserted and the reservoir height was fixed at a constant height so that the flow rate of the aqueous solution could be maintained at a fixed value. A four-electrode potentiostat/galvanostat (Huso Electrochemical System, HECS-310B) was combined with a laboratory-made instrument for compensating the iR-drop due to solution resistance. Reference electrodes in the nitrobenzene and aqueous phases were $\mathrm{Ag} / \mathrm{AgCl}$ electrodes, and auxiliary electrodes in both phases were platinum electrodes.

The electrolytic cell for ion-transfer voltammetry was 


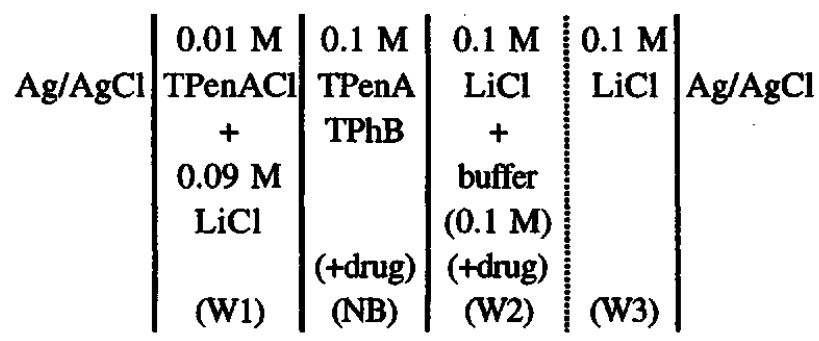

where TPenACl is tetrapentylammonium chloride, and TPenATPhB is tetrapentylammonium tetraphenylborate. Each drug was added to aqueous phase $\mathrm{W} 2$ containing a $\mathrm{pH}$ buffer solution or phase NB.

\section{Reagents}

TPenATPhB was prepared by mixing an ethanol solution of tetrapentylammonium iodide with an ethanol solution of sodium tetraphenylborate and purified by recrystallization from an acetoneethanol mixture. Nitrobenzene (analytical grade

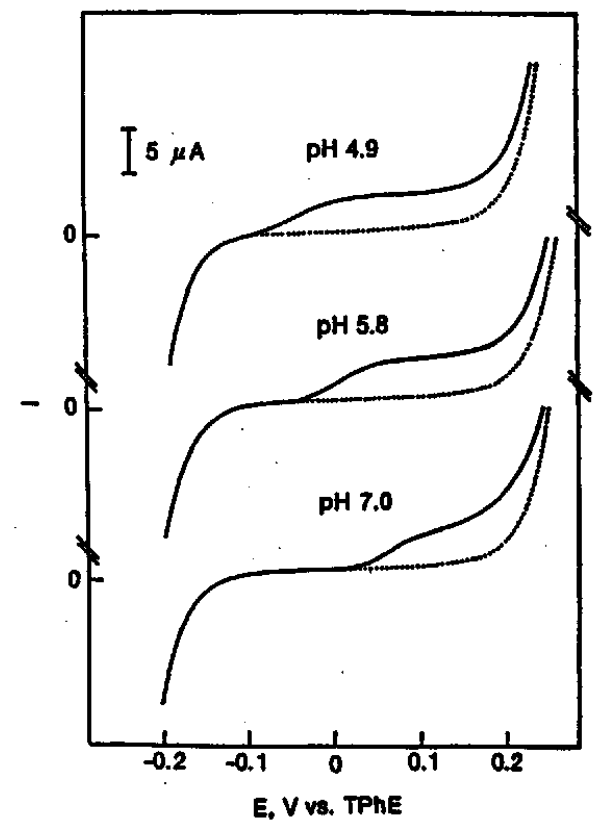

Fig. 1 Voltammograms in the presence of 0.2 mM nicardipine in NB at various $\mathrm{pH}$. Scan rate: $\mathbf{0 . 2}$ $\mathbf{m A} / \mathbf{s}$.

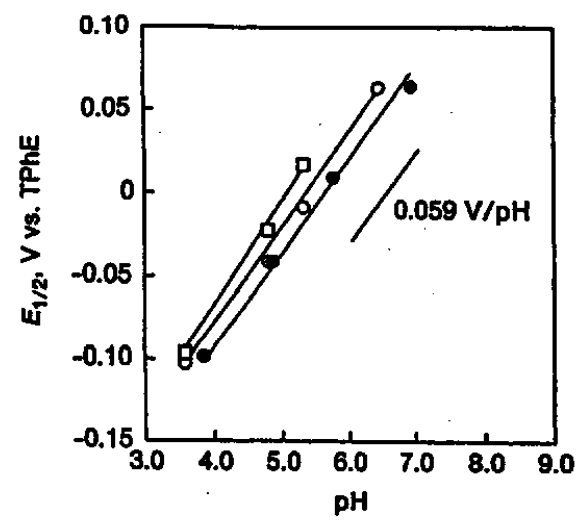

Fig. 2 Plots of the half-wave potential of the voltammogram in the presence of nicardipine $(\theta)$, barnidipine (O), and benidipine ( $\square$ ) vs. pH. from Wako Pure Chemicals) was washed with water three times just before use. Water used in this study was distilled and then purified with a Nano Pure II filtering system (Barnstead Co.). The other chemicals were obtained commercially and were used without further purification.

\section{Results and Discussion}

\section{Calcium antagonists}

Nicardipine, barnidipine and benidipine were used as calcium antagonists. Each drug in the neutral form was added to NB because of its low solubility in water. Figure 1 shows the voltammograms obtained in the presence of 0.2 $\mathrm{mM}$ (solid line) and $0 \mathrm{M}$ (dotted line) nicardipine in $\mathrm{W} 2$ at $\mathrm{pH} 4-8$. In the voltammograms, the anodic current (positive current) corresponds to the transfer of cations from $\mathrm{W} 2$ to NB or anions from NB to W2. The final anodic and cathodic current rises correspond to the transfer of supporting electrolyte ions in the aqueous and/or nitrobenzene phases. At each $\mathrm{pH}$, an anodic wave was observed in the potential window when nicardipine was present in NB. The limiting current $\left(I_{d}\right)$ increased linearly with nicardipine concentration added to NB. Figure 2 shows plots of $E_{1 / 2}$ of nicardipine, barnidipine, and benidipine versus $\mathrm{pH}$. $E_{1 / 2}$ becomes more positive by $0.059 \mathrm{~V}$ per unit $\mathrm{pH}$ over the $\mathrm{pH}$ range. $I_{d}$ was independent of $\mathrm{pH}$. Essentially the same behavior was obtained using barnidipine and benidipine. Though nifedipine and isradipine have a main structure similar to nicardipine, no voltammetric wave corresponding to the drugs was seen. The chemical structures of the calcium antagonists in this study are shown in Fig. 3. Nicardipine, barnidipine, and benidipine are tertiary amines and are weak bases. They are ionized by accepting protons in the aqueous and nitrobenzene phases. Protons or ionized drugs can be transferred at the interface, thus showing a voltammetric wave. Nifedipine and isradipine have no ability to accept protons at the $\mathrm{pH}$ in this study and remain in the neutral forms. Thus no voltammetric wave was seen.

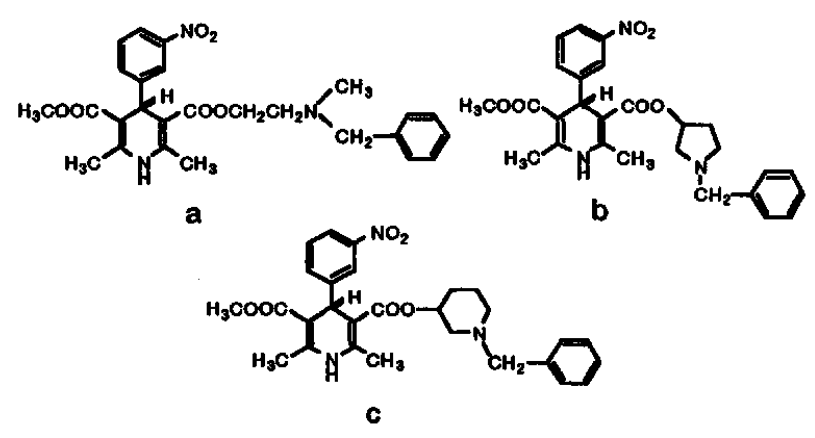

Fig. 3 Chemical structures of calcium antagonists: (a) nicardipine, (b) barnidipine, (c) benidipine. 


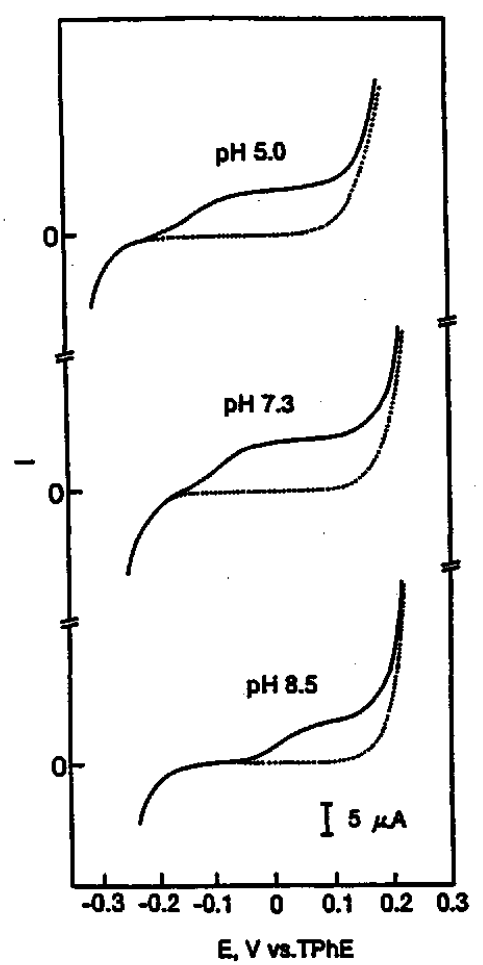

Fig. 4 Voltammograms in the presence of 0.2 $\mathrm{mM}$ propranolol in $\mathrm{W} 2$ at various $\mathrm{pH}$. Scan rate: $\mathbf{0 . 2}$ $\mathrm{mA} / \mathrm{s}$.

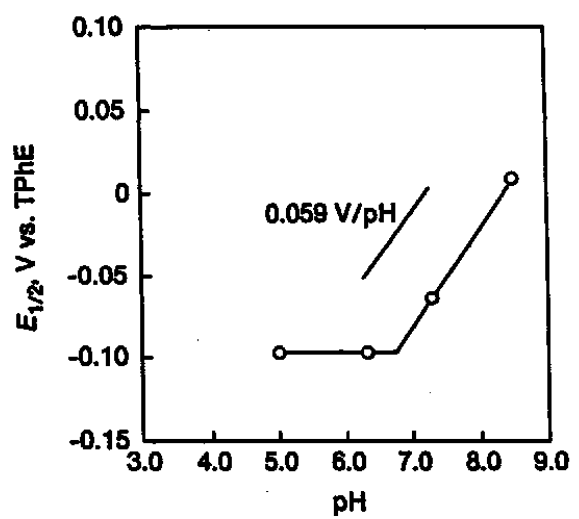

Fig. 5 Plots of the half-wave potential of the voltammogram in the presence of propranolol vs. pH.

\section{Propranolol}

Fig. 4 shows the ion-transfer voltammograms in the presence of $0.2 \mathrm{mM}$ propranolol hydrochloride in $\mathrm{W} 2$ at $\mathrm{pH}$ 5-8.5. Each voltammogram showed a reversible anodic wave. $I_{d}$ increased with propranolol concentration and was independent of pH. $E_{1 / 2}$ becomes more positive by $0.059 \mathrm{~V}$ per unit $\mathrm{pH}$ at $\mathrm{pH}$ values above 6 (Fig. 5), whereas below $\mathrm{pH}$ $6, E_{1 / 2}$ remained constant.

\section{Acetylcholine}

The ion-transfer voltammograms in the presence of $0.2 \mathrm{mM}$ acetylcholine chloride in W2 are shown

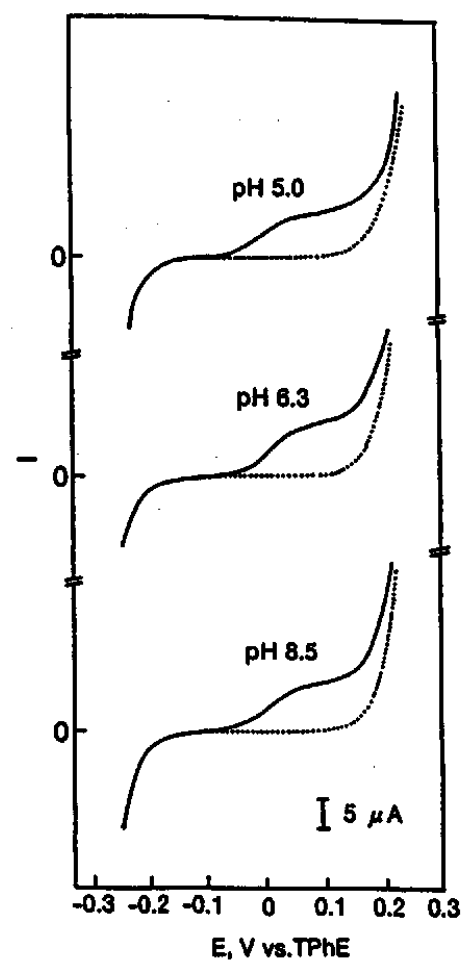

Fig. 6 Voltammograms in the presence of 0.2 $\mathrm{mM}$ acetylcholine in $\mathrm{W} 2$ at various $\mathrm{pH}$. Scan rate: $0.2 \mathrm{~mA} / \mathrm{s}$.

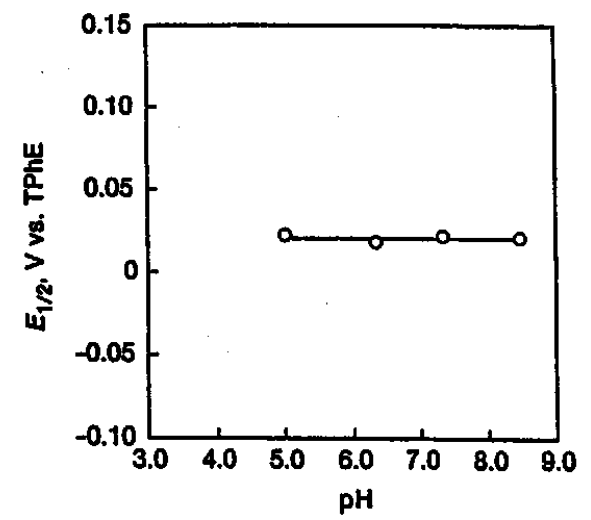

Fig. 7 Plots of the half-wave potential of the voltammogram in the presence of acetylcholine vs. $\mathrm{pH}$.

in Fig. 6. $I_{d}$ increased with acetylcholine concentration and was independent of $\mathrm{pH}$. A reversible anodic wave was seen in each voltammogram. As shown in Fig. $7, E_{1 / 2}$ was independent of $\mathrm{pH}$ at $\mathrm{pH} 5-8.5 . E_{1 / 2}$ obtained was $0.041 \mathrm{~V}$ vs. TPhE, a value essentially the same as that in the literature.

pH dependence of half-wave potential

Three types of $\mathrm{pH}$ vs. $E_{1 / 2}$ plots were obtained.

Propranolol: having two regions; one where $E_{1 / 2}$ increases with $\mathrm{pH}$ and the other 
where $E_{1 / 2}$ is independent of $\mathrm{pH}$ (Type I)

Nicardipine, barnidipine, and benidipine: $E_{1 / 2}$ increases with $\mathrm{pH}$ (Type II)

Acetylcholine: $E_{1 / 2}$ is independent of $\mathrm{pH}$ (Type III)

Since propranolol, nicardipine, barnidipine, and benidipine are amines, the ionization of the drugs in the aqueous phase and the distribution of the neutral drugs between the nitrobenzene and aqueous phases should participate in the ion transfer process. For deriving the $E_{1 / 2}$ equations for ion transfer of a drug, the following conditions were assumed:

(1) The dissociation of a drug in the nitrobenzene phase and ion pair formation with supporting electrolyte ions are negligible.

(2) The aqueous phase is well buffered so that protons at the interface are readily available in abundance relative to ion transfer.

(3) All equilibrium reaction rates participating in the ion transfer are much higher than that of the ion transfer.

Thus, the $E_{1 / 2}$ equations ${ }^{4}$ for ion transfer of drugs are given as Eqns. 1 and 2 :

$$
\begin{aligned}
& \text { Case I: } \\
& \left(K_{\mathrm{a}} /\left[\mathrm{H}^{+}\right]\right) K_{\mathrm{D}}\left(D^{\mathrm{O}} / D^{\mathrm{W}}{ }_{\mathrm{B}}\right)^{1 / 2}<<1 \\
& \text { (that is, } \left.\mathrm{pH}<\mathrm{p} K_{\mathrm{a}}-\log K_{\mathrm{D}}-\log \left(D^{\mathrm{O}}{ }_{\mathrm{B}} / D^{\mathrm{w}}{ }_{\mathrm{B}}\right)\right) \\
& \quad E_{1 / 2}=E^{0}+(R T / 2 z F) \ln \left(D^{\mathrm{W}}{ }_{\mathrm{BH}^{+}} / D^{\mathrm{o}}{ }_{\mathrm{BH}}{ }^{+}\right)
\end{aligned}
$$

$$
\begin{aligned}
& \text { Case II: } \\
& \left(K_{\mathrm{a}} /\left[\mathrm{H}^{+}\right]\right) K_{\mathrm{D}}\left(D^{\circ}{ }_{\mathrm{B}} / D^{\mathrm{w}}{ }_{\mathrm{B}}\right)^{1 / 2} \gg 1 \\
& \text { (that is, } \mathrm{pH}>\mathrm{p} K_{\mathrm{a}}-\log K_{\mathrm{D}}-\log \left(D_{\mathrm{B}}^{\mathrm{O}} / D^{\mathrm{w}}{ }_{\mathrm{B}}\right) \text { ) } \\
& E_{1 / 2}=E^{0}+(R T / 2 z F) \ln \left(D^{\mathrm{W}}{ }_{\mathrm{BH}^{+}} / D_{\mathrm{BH}^{+}}^{\mathrm{O}}\right) \\
& +(R T / z F) \ln K_{\mathrm{a}}+(R T / z F) \ln K_{\mathrm{D}} \\
& \text { - }(R T / z F) \ln \left[\mathrm{H}^{+}\right]
\end{aligned}
$$

where $R$ is the gas constant, $T$ absolute temperature, $z$ ion charge, $F$ Faraday's constant, $K_{\mathrm{a}}$ dissociation constant in the aqueous phase, and $K_{\mathrm{D}}$ partition coefficient. $D$ is the diffusion constant whose superscripts $w$ and $o$ stand for the aqueous and organic phases, respectively, and subscripts B and $\mathrm{BH}^{+}$, the molecular and ion forms of a drug, respectively. $E^{0}$ is the standard potential of ion transfer defined by $\Delta G^{0}=-z F E^{0}$, with $\Delta G^{0}$ the standard Gibbs energy of ion transfer. Accordingly, $E_{1 / 2}$ of the drugs should become more positive by $0.059 \mathrm{~V}$ per unit $\mathrm{pH}$ at $\mathrm{pH}>\mathrm{p} K_{\mathrm{a}}-\log K_{\mathrm{p}}-\log \left(D_{\mathrm{B}}^{\mathrm{O}} /\right.$ $\left.D^{\mathrm{w}}{ }_{\mathrm{B}}\right)$, whereas at $\mathrm{pH}<\mathrm{p} K_{\mathrm{a}}-\log K_{\mathrm{D}}-\log \left(D_{\mathrm{B}}^{\mathrm{O}} / D^{\mathrm{w}}{ }_{\mathrm{B}}^{\mathrm{B}}\right)$, $E_{1 / 2}$ should remain constant. From Eqn. 2, the $E_{1 / 2}$ value obtained from a voltammogram at $\mathrm{pH}<\mathrm{p} K_{\mathrm{a}}$ $\log K_{\mathrm{D}}-\log \left(D_{\mathrm{B}}^{\mathrm{o}} / D^{\mathrm{W}}{ }_{\mathrm{B}}\right)$ can be thought of as $E_{1 / 2}$ of the drug ion itself, though the anodic waves in the voltammograms in Figs. 1 and 4 may be due to the proton transfer facilitated by neutral propranolol in NB,

The $\mathrm{p} K_{\mathrm{a}}$ of propranolol was obtained from the literature ${ }^{9}$ and $\log \left(D_{\mathrm{BH}+}^{\mathrm{O}} / D_{\mathrm{BH}_{+}}^{\mathrm{W}}\right)$ was determined from the peak height ratio of anodic and cathodic waves in the cyclic voltammogram. $\log K_{\mathrm{D}}$ was determined by potentiometric titration. Thus, $\mathrm{p} K_{\mathrm{a}}$ $\log K_{\mathrm{D}} \log \left(D_{\mathrm{B}}^{\mathrm{O}} / D^{\mathrm{w}}{ }_{\mathrm{B}}\right)$ is estimated as 6.8 That is, $E_{1 / 2}$ of the drugs should become more positive by 0.059 $\mathrm{V}$ per unit $\mathrm{pH}$ at $\mathrm{pH}>6.8$, whereas at $\mathrm{pH}<6.8, E_{1 / 2}$ should remain constant. This is very consistent with a pH vs. $E_{1 / 2}$ plot in Fig. 2 , and the $E_{1 / 2}$ equations could be applied to propranolol, as well as scopolamine and lidocaine. This kind of drug shows a $\mathrm{pH}$ vs. $E_{1 / 2}$ plot of Type $I$.

For nicardipine, barnidipine and benidipine, the $\mathrm{pH}$ dependence of $E_{1 / 2}$ according to Eqn. 1 was seen over the pH range. A pH-independent region may possibly be present at a lower $\mathrm{pH}$. At this time, the anodic wave must be shown at a more negative potential, which is far out of the potential window. Thus, the $\mathrm{pH}$-independent region could not be seen. This may be due to the large $\mathrm{p} K_{\mathrm{D}}$ values of the calcium antagonists. This type of drug shows a $\mathrm{pH}$ vs. $E_{1 / 2}$ plot of Type II.

Acetylcholine is a quaternary ammonium ion and thus, the $E_{1 / 2}$ value obtained was that of the drug ion itself without regard to Eqns. 1 and 2. A plot of Type III is shown by this kind of drug.

The $\mathrm{pH}$ vs. $E_{1 / 2}$ plots of calcium antagonists, propranolol, and acetylcholine were successfully explained by the $E_{1 / 2}$ equations for ion transfer of drugs based on the ionization of the drugs in the aqueous phase and the distribution of the neutral drugs between the nitrobenzene and aqueous phases. Since ion-transfer voltammetry provides thermodynamic parameters such as the free energy of ion transfer and the partition coefficient of drugs, this method is a promising one for clarifying drug behavior at biomembranes such as adsorption and transport of a drug through a biomembrane.

\section{References}

1) J. J.Zimmerman and S. Feldman, in Principles of Medicinal Chemistry, Ed. W. O. Foye, chap. 2, Lea and Febiger 1974.

2) C. Gavach, T. Mlodnicka and J. Guastalla, $C$. $R$. Acad. Sci., Paris, Ser. C, 266, 1196 (1968).

3) K. Arai. F. Kusu and K. Takamura, in LiquidLiquid Interfaces. Theory and Methods, Ed. A. G. Volkov and D. W. Deamer, chap. 17, CRC Press, 1996.

4) K. Arai, F. Kusu, N. Tsuchiya, S. Fukuyama and K. Takamura, Denki Kagaku, 62, 840 (1994).

5) S. Kihara, Z. Yoshida and T. Fujinaga, Bunseki Kagaku, 31, E297 (1982).

6) Y. Shao, J. A. Campbell and H. H. Girault, $J$. Electroanal. Chem., 300, 415 (1991).

7) V. Marecek and Z. Samec, Anal. Lett., 14, 1241 (1981).

8) K. Arai, M. Ohsawa, F. Kusu and K. Takamura, Bioelectrochem. Bioenerg., 31, 65 (1993).

9) G. S. Avery, Ed., Drug Treatment, Publishing Science Group, pp. 890-896, 1976. 